\title{
APPLICATION OF NUMERICAL MODELING TO OPTIMIZE THE THERMAL CYCLE OF THE INTERNAL COMBUSTION ENGINE
}

\author{
Arkadiusz Jamrozik, Wojciech Tutak \\ Institute of Thermal Machinery, Czestochowa University of Technology, Poland \\ jamrozik@imc.pcz.czest.pl,tutak@imc.pcz.czest.pl
}

\begin{abstract}
The paper presents the results of numerical modeling of the complete thermal cycle of the Andoria 1hc102 test engine. Modeling was carried out in the AVL Fire program. Modeling was used in order to determine the optimal ignition angle of the test IC internal combustion (IC) engine. Model tests were carried out for the spark ignition (SI) engine to operate with excess air ratio equal to $\lambda=1.2$. As a criterion for estimating the quality of engine operation cycle, a value of maximum indicated pressure and indicated efficiency were taken. An additional criterion taken was the so-called knock combustion that limits engine performance. Courses of heat release rate and total heat release as a result were obtained. Modeling results show that the test engine powered by a lean mixture of $\lambda=$ $=1.2$, should work with the ignition advance angle equal to $12 \mathrm{deg}$ before top dead centre (BTDC). At this ignition advance angle in the engine knock occurred and the engine reached the indicated pressure and the indicated efficiency and were equal to respectively $0.82 \mathrm{MPa}$ and $34.6 \%$.
\end{abstract}

\section{Introduction}

During recent years, the numerical modeling research using more and more advanced mathematical models has been intensively developing. The development of numerical modeling is heightened by increasing computational power that allows modeling not only flow processes but also combustion in 3D [1-3]. One of more advanced numerical models used for combustion process in piston engines modeling is AVL Fire [4]. In 2009 the Institute of Internal Combustion Engines and Control Engineering of Czestochowa University of Technology began a University Partnership Program with the AVL Company and to modeling thermal cycle of IC engines using AVL Fire software [5-7].

The AVL Fire software belongs to contemporary programs which are used to model the thermal cycle of internal combustion engines. Fire allows modeling flow and thermal processes occur in the intake manifold, in the combustion chamber of IC engine and exhaust pipe with a catalyst and a particulate filter. This programme allows for the calculation of transport phenomena, mixing, ignition and turbulent combustion in internal combustion engine. Homogeneous and inhomogeneous 
combustion mixtures in spark ignition and compression ignition engine can be modeled using this software as well. Kinetics of chemical reactions phenomena is described by combustion models which take oxidation processes in high temperature into consideration. Several models apply to auto ignition processes. AVL Fire allows for the modeling knock process which occurs in combustion chamber of IC engine. This program allows building three-dimensional computational greed, characterise of boundary conditions of surfaces and initial conditions of simulation. The postprocessor gives possibility to visualization of results.

This paper presents results of numerical optimization of the ignition advance angle using AVL Fire software in the modernized the Andoria 1 hc102 test engine, during the combustion of fuel mixture of excess air factor $\lambda=1.2$. The optimum value of the ignition angle was taken for the maximum indicated pressure $p_{i}$ and indicated efficiency $\eta_{i}$, and for which there was no combustion knock.

The knock is a type of abnormal combustion process, characterized by intense pressure pulsations in the combustion chamber, which are transferred to the block engine, generate a distinctive sound and could lead to engine damage. The source of combustion knock is auto-ignition unburned gases before the flame front (initiated by a spark plug) by a big increase in temperature and pressure [8-11].

\section{Numerical model}

The test engine was constructed on the basis of a four-stroke compressionignition engine 1hc102 manufactured by "ANDORIA" Diesel Engine Manufacturers of Andrychow. After some constructional changes, this engine was redesigned for the combustion of gasoline as a spark ignition engine. Figure 1a shows the experimental modernized the combustion chamber of the Andoria 1hc102 test engine.

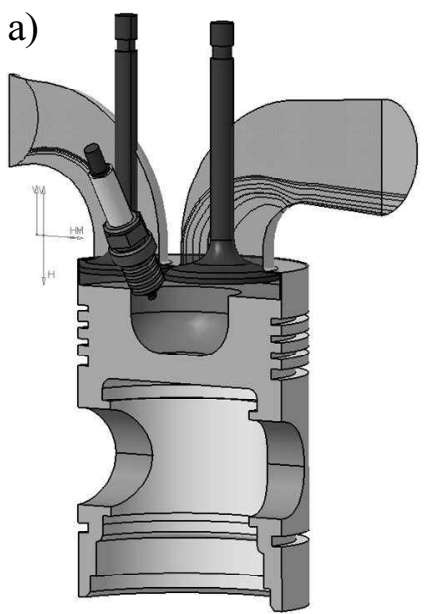

b)

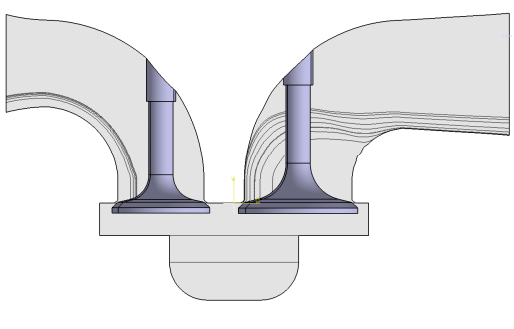

Fig. 1. Geometry of engine in CAD 
Table 1

Main engine parameters

\begin{tabular}{|l|c|}
\hline cylinder bore & $100 \mathrm{~mm}$ \\
\hline stroke & $120 \mathrm{~mm}$ \\
\hline connecting rod length & $216 \mathrm{~mm}$ \\
\hline direction of cylinders & horizontal \\
\hline squish & $11 \mathrm{~mm}$ \\
\hline compression ratio & 8.5 \\
\hline engine speed & $1500 \mathrm{rpm}$ \\
\hline number of cylinders & 1 \\
\hline
\end{tabular}

The engine was equipped with a new fuel supply system and an ignition installation. As a result of modernization the shape of the combustion chamber was changed and the compression ratio was reduced from 17 to 8.5. The engine is a stationary, two-valve unit with a horizontal cylinder configuration. The engine cooling system is the evaporation of the water jacket. A three-dimensional mesh of a combustion chamber of engine was built on the basis of the real dimensions of the experimental engine (Fig. 2).

Valve lifts curves were determined by measuring the engine cams. The modeling takes into account the intake and exhaust channels located in the engine head.
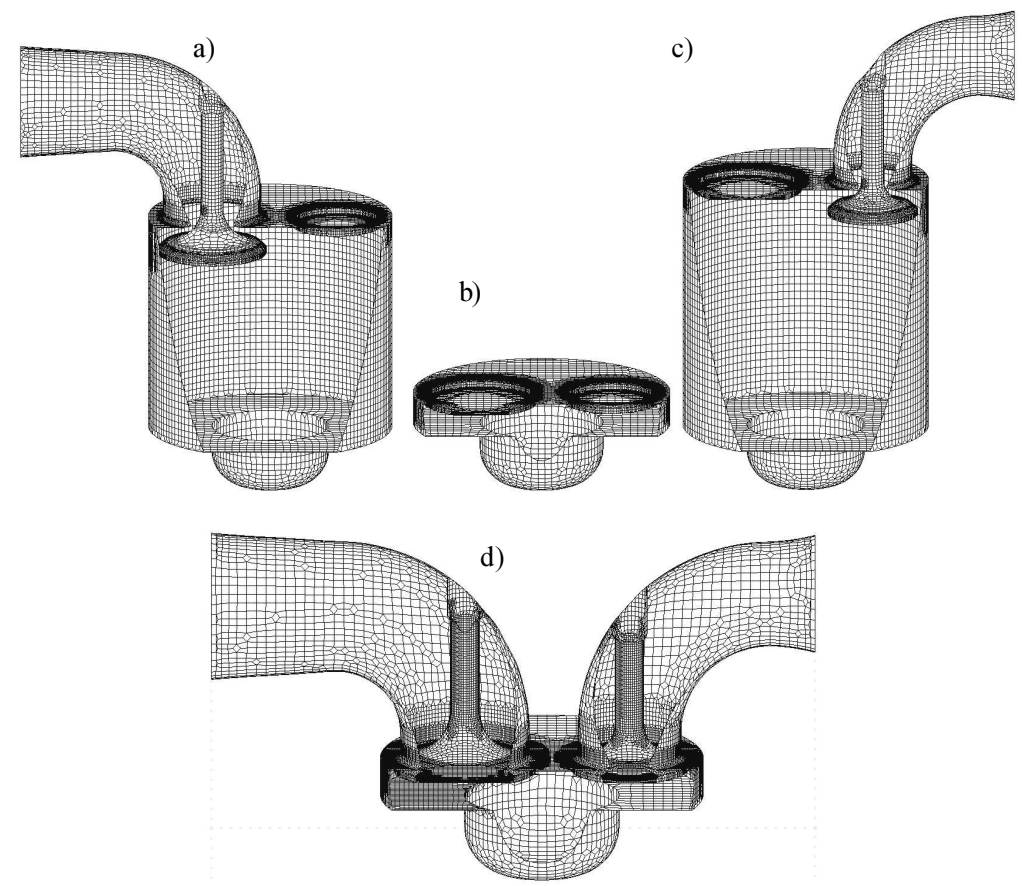

Fig. 2. Computational mesh of engine: a) intake, b) compression, c) exhaust, d) complete mesh 
The computational mesh can be obtained as surface or volume discretization. In AVL Fire the Finite Volume Method (FVM) is used to calculate the heat flows. For a four stroke engine four computational domains are required. The first domain includes the intake stroke until close the intake valve. The second domain is used when the valves are closed, from the intake valve closing until the exhaust valve opening. The third domain is used from the exhaust valve opening until the end of the exhaust stroke. And finally the fourth domain is required for the whole engine cycle. The division cycle of three domains eliminates the problem of return flows in the crevices between the valve train and valve seat.

The first step is to draw the engine workspace. Due to the requirements of software, both valves must be slightly open. This geometry is loaded into the preprocessor of Fire program. On the basis of this geometry the computational moving mesh is generated (Fig. 2).

The computational mesh around valves was concentrated to obtain more accurate results. Fire gives the possibility of temporary thickening of the grid.

Modeling of the thermal cycle of the test spark ignition engine in the AVL Fire [4] software was carried out. Modeling of combustion process was carried out using an advanced combustion model. ECFM (Extended Coherent Flame Model) model was used based on the basis of turbulent mixing zone of air, fuel and exhaust. The ECFM has been developed in order to describe combustion in spark ignition engines. This model allows the modeling of the combustion process of airfuel mixtures with EGR effect and NO formation. The model is based on the description of unburned and burnt zones of the gas. The concept of the combustion model is based on a laminar flamelet idea, whose velocity and thickness are mean values, integrated along the flame front. The thickness of the flame front layer depends on the pressure, the temperature and content of unburned fuel in the fresh zone. In addition, it is assumed that reaction takes place within relatively thin layers that separate the fresh unburned gas from the fully burnt gas. This model uses a 2-step chemistry mechanism for the fuel conversion. The unburned gas phase consists of 5 main unburned species: fuel, $\mathrm{O}_{2}, \mathrm{~N}, \mathrm{CO}_{2}$ and $\mathrm{H}_{2} \mathrm{O}$. The burnt gas phase it is assumed that no fuel remains. The burnt gas is composed of 11 species, such as $\mathrm{O}, \mathrm{O}_{2}, \mathrm{~N}, \mathrm{~N}_{2}, \mathrm{H}, \mathrm{H}_{2}, \mathrm{CO}, \mathrm{CO}_{2}, \mathrm{H}_{2} \mathrm{O}, \mathrm{OH}$ and $\mathrm{NO}$.

\section{Calculations assumptions}

The calculation started at TDC at the beginning of the intake stroke, proceeded through the total cycle of 1080 degrees and finished at the end of engine exhaust stroke. At the beginning of calculations, the lean mixture of excess air factor equal to 1.2 was in the chamber. The modeling of combustion process was conducted for a range of ignition advance angle from 38 to $8 \mathrm{deg}$ of crank angle BTDC in order to optimize the thermal cycle of the test engine. On the basis of the pressure data were calculated indicated pressure and indicated efficiency. Using AVL Fire software a computational analysis was conducted of the potential combustion knock. 
Table 2

Modeling parameters and submodels

\begin{tabular}{|l|c|}
\hline ignition advance angle & $8 \div 36 \mathrm{deg}$ \\
\hline ignition duration & $10 \mathrm{deg}$ \\
\hline fuel & gasoline \\
\hline temperature of fuel injection & $320 \mathrm{~K}$ \\
\hline initial pressure & $1.0 \mathrm{e}+5 \mathrm{~Pa}$ \\
\hline initial temperature & $365 \mathrm{~K}$ \\
\hline excess air factor & 1.2 \\
\hline density & $1.19 \mathrm{~kg} / \mathrm{m}^{3}$ \\
\hline turbulence kinetic energy & $0.1 \mathrm{~J} / \mathrm{m}^{3}$ \\
\hline turbulence length scale & $1.12 \mathrm{~cm}$ \\
\hline combustion model & ECFM-3Z \\
\hline turbulence model & $\mathrm{k}-\mathrm{zeta}-\mathrm{f}$ \\
\hline knock model & AnB \\
\hline
\end{tabular}

One of the parameters determining the performance of the combustion engine is the indicated pressure [12]

$$
p_{i}=\frac{\sum_{180}^{540} \frac{p_{n}+p_{n+1}}{2}\left(V_{n+1}-V_{n}\right)}{V_{s}}
$$

where $p_{n}, p_{n+1}$ are instantaneous values of the pressure in the cylinder, MPa, $V_{n}$, $V_{n+1}$ are instantaneous values of the cylinder volume, $\mathrm{m}^{3}, V_{s}$ is displacement volume, $\mathrm{m}^{3}$.

The average value of the indicated efficiency, expressed in $\%$ is equal to:

$$
\eta_{i}=\frac{p_{i} V_{s}}{Q} 100 \%
$$

where $Q$ is total heat supplied to the engine, MJ.

The heat supplied to the engine cylinder:

$$
Q=\frac{V \rho W}{0.5 n t}
$$

where $V$ is the volume of gasoline delivered to the engine cylinder, $\mathrm{m}^{3}, \rho$ is the density of gasoline, $\mathrm{kg} / \mathrm{m}^{3}, W$ is the calorific value of gasoline, $\mathrm{MJ} / \mathrm{kg}, n$ is the speed engine, rpm, $t$ is the time consumption of gasoline delivered to the engine cylinder, min. 


\section{Results of modeling}

As a result of numerical analysis a number of characteristic quantities of the combustion process in the engine were obtained such as: pressure, temperature, parameters of flow field, turbulence, heat transfer, species, toxic parameters and other. As a result of calculation the pressure courses were obtained as a function of the crank angle for the whole analyzed range of the ignition advance angle (Fig. 3).

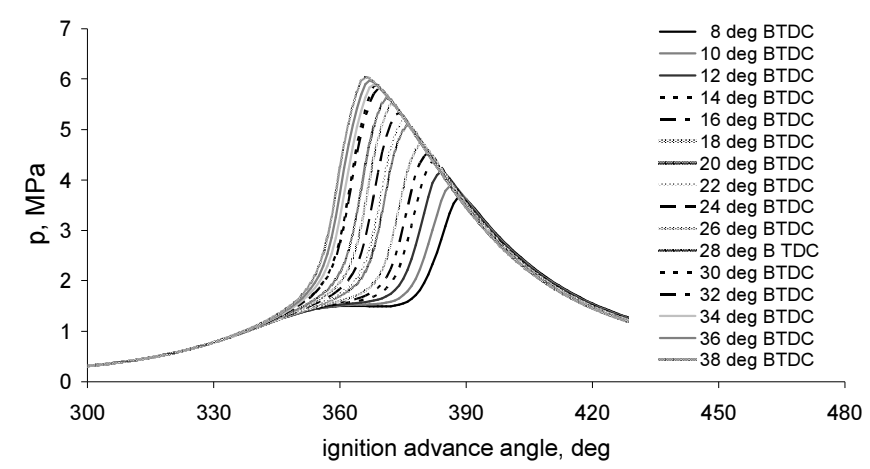

Fig. 3. Courses of pressure for the analyzed range of the ignition advance angle

In Figure 4 the flow field in the modeled engine during the intake stroke is presented. The main swirl process by the streamlines is underlined. There the socalled tumble swirl is visible. This swirl is responsible for the direction of the flame kernel propagation.

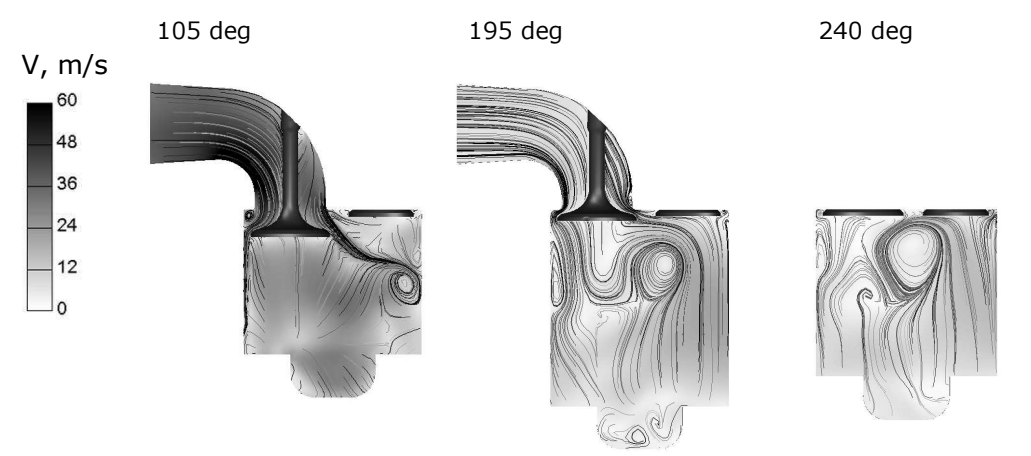

Fig. 4. Cross sections of the engine cylinder during intake stroke - velocity field with streamlines

Figure 5 shows the cross sections of the engine cylinder which the temperature field is presented. The first picture shows flame propagation in the combustion chamber. The direction of flame propagation is determined by fluid flows generated during intake stroke (Fig. 4). In Figure 4 the tumble flow is highly visible. The 
second two pictures show the exhaust stroke when the exhaust valve starts to open and when it is full open.
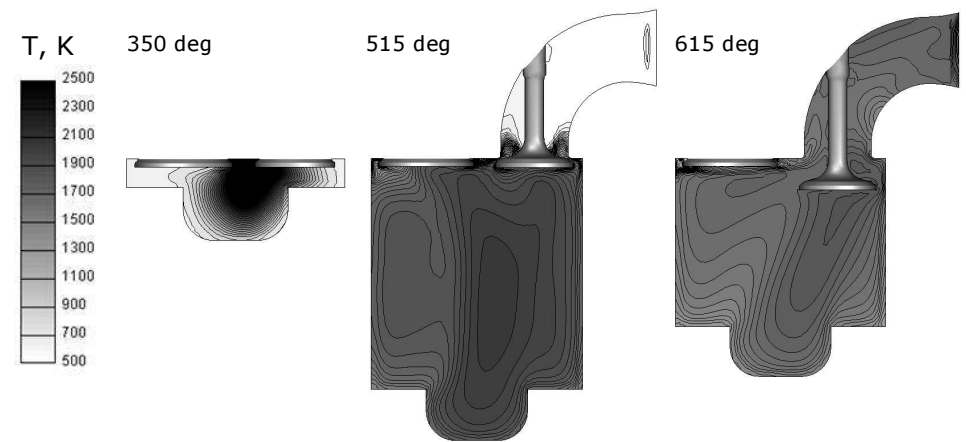

Fig. 5. Cross sections of the engine cylinder at the beginning of combustion and during exhaust stroke - temperature

Figure 6 shows the indication parameters of the engine model calculated on the basis of pressures.

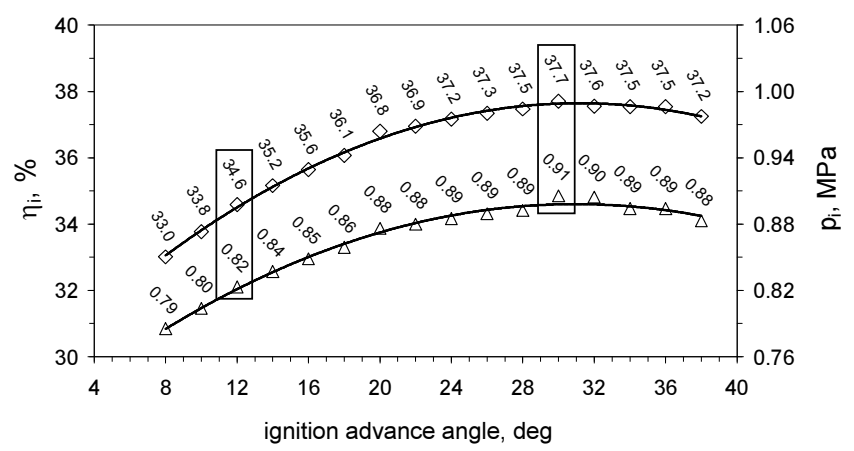

Fig. 6. The value of indicated pressure and indicated efficiency for the analyzed range of the ignition advance angle

The obtained results of modeling show that the angle is equal to 30 deg before TDC is the most suitable of ignition advance angle for the engine parameters. For this ignition angle the maximum indicated pressure achieved, is equal to $0.91 \mathrm{MPa}$ and the highest indicated efficiency is equal to $37.7 \%$. Unfortunately, the consequence of using such a large ignition advance in the test engine causes the creation of combustion knock (Figs 7 and 8) [13, 14].

In the used knock AnB model, the Knock Reaction Rate (KRR) is one of the values characterizing the process of knocking. It is a dimensionless quantity defining rapid rate of heat release in the zone of unburned mixture, which indicates the occurrence and speed of combustion knock. KRR is a function of the Arrhenius terms [4] 


$$
k_{i}=A_{i} e^{-E i / R T}
$$

where $A_{i}$ is constant, $E i$ is activation temperature, $\mathrm{K}, R$ is universal gas constant, $\mathrm{J} / \mathrm{kmol} \cdot \mathrm{K}, T$ is temperature, $\mathrm{K}$.
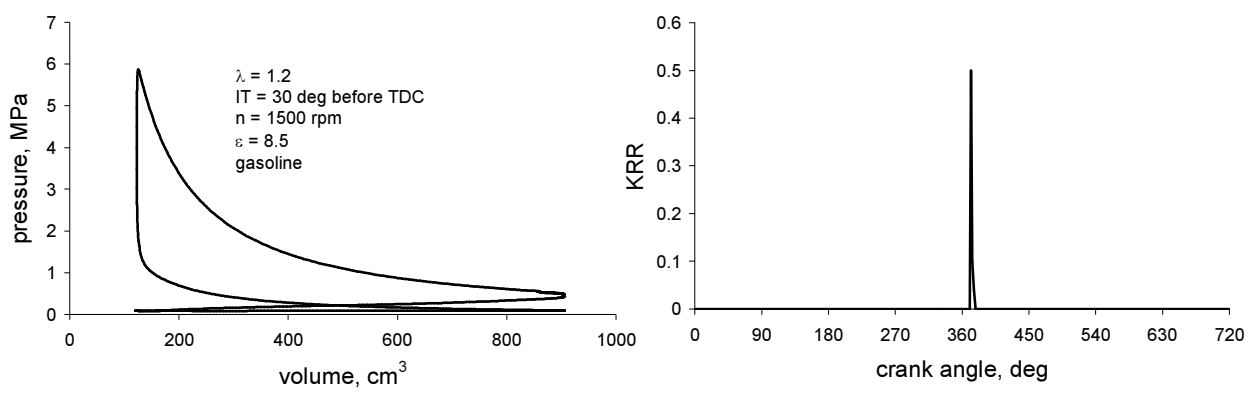

Fig. 7. Pressure and Knock Reaction Rate courses for ignition advance angle equal 30 deg BTDC

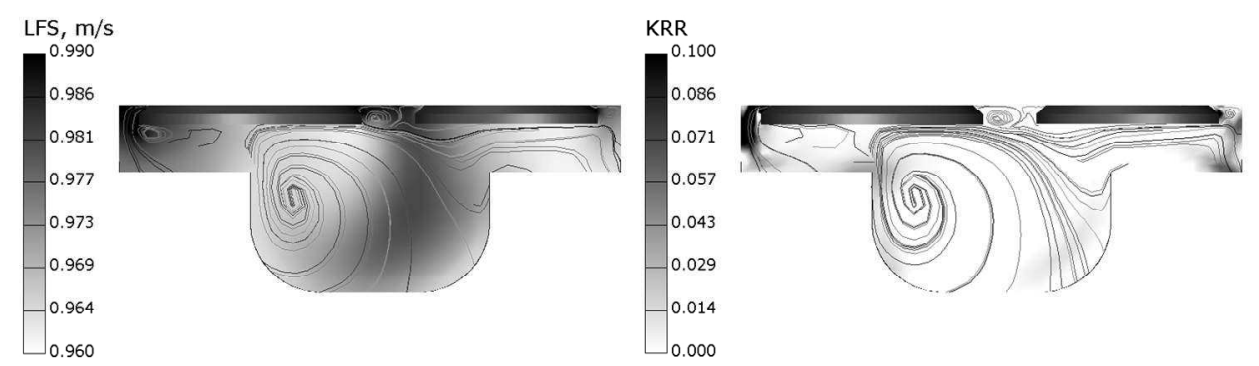

Fig. 8. Laminar Flame Speed and Knock Reaction Rate distribution at 10 deg ATDC for ignition advance angle equal to $30 \mathrm{deg}$ BTDC

The knock combustion process also occurred at smaller advance angles, at 14 deg before TDC. For this engine, the normal combustion process occurs to the ignition angle equal to $12 \mathrm{deg}$ before TDC (Fig. 9). For the ignition angles larger than 12 deg BTDC in this engine a knock occurs.
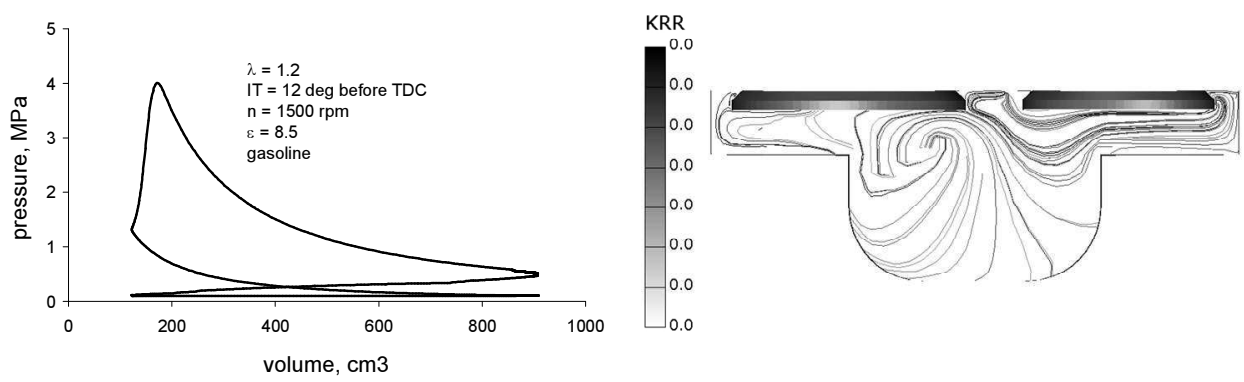

Fig. 9. Pressure courses and Knock Reaction Rate distribution at 10 deg ATDC for ignition advance angle equal to $20 \mathrm{deg}$ BTDC 


\section{Conclusions}

The AVL FIRE program is a modern research tool that can be successfully used to model the complete thermal cycle of the internal combustion engine. The AVL FIRE up-to-date numerical code used during researches makes it possible to generate $3 \mathrm{D}$ geometric mesh of combustion chambers of the test engine and allows us to perform numerical calculations of processes occurring in this engine. Conducted simulations of combustion process have delivered information concerning spatial and time-dependent pressure and Laminar Flame Speed and Knock Reaction Rate distribution in combustion chamber. This information would be extremely difficult to obtain by experimental methods. It allows us to analyzing not only the combustion chamber but also the intake and exhausting process. The ability to detect knock in the cylinder can identify the real engine operating parameters at the optimum settings. In the paper, using AVL Fire found the optimal value of the ignition advance angle for a modernized $1 \mathrm{hc} 102$ Andoria engine which is powered by a combustible mixture with an excess air factor of 1.2. The optimum value of the angle was that which occurred at the maximum indicated pressure and indicated efficiency, and for which there was no combustion knock. As a result of modeling it can be concluded that combustion of a mixture of $\lambda=1.2$, the engine should work with the ignition advance angle equal to $12 \mathrm{deg}$ before TDC. At this ignition angle in the engine does not occurs an undesirable symptom as combustion knock and obtained values of the indicated pressure and the indicated efficiency were equal to respectively $0.82 \mathrm{MPa}$ and $34.6 \%$.

The numerical modeling using the AVL FIRE can be used for preliminary determination of adjustable engine parameters such as ignition advance angle, without using a real engine on the testing stand. Using numerical methods to optimize engine operation can and should be verified by experiment, however, on the measuring stand.

\section{Acknowledgements}

The authors would like to express their gratitude to AVL LIST GmbH for Providing a AVL Fire software under the University Partnership Program.

\section{References}

[1] Jamrozik A., Modelling of two-stage combustion process in SI engine with prechamber, Proceedings of the V-th International Conference MEMSTECH 2009, Perspective Technologies and Methods in MEMS Design, Lviv-Polyana 2009, 13-16.

[2] Jamrozik A., Numerical analysis of mixture creation and combustion in SI engine with prechamber, TEKA PAN, Commission of Motorization, 33-34, Krakow 2008, 143-150.

[3] Tutak W., Modelling of flow processes in the combustion chamber of IC engine, Proceedings of the V-th International Conference MEMSTECH 2009, Perspective Technologies and Methods in MEMS Design, Lviv-Polyana 2009, 45-48. 
[4] AVL FIRE version 2009, ICE Physics \& Chemistry, Combustion, Emission, Spray, Wallfilm, AVL LIST GmbH, 2009.

[5] Jamrozik A., Tutak W., Modelling of combustion process in the gas test engine, Proceedings of the VI-th International Conference MEMSTECH 2010, Perspective Technologies and Methods in MEMS Design, Lviv-Polyana 2010, 14-17.

[6] Tutak W., Jamrozik A., Numerical analysis of some parameters of gas engine, TEKA PAN, Commission of Motorization and Power Industry in Agriculture 2010, X, 491-502.

[7] Tutak W., Jamrozik A., Modelling of the thermal cycle of gas engine using AVL FIRE Software, Combustion Engines 2010, 2(141), 105-113.

[8] Szwaja S, Jamrozik A., Analysis of combustion knock in the SI engine, Combustion Engines 2009-SC2, 2009, 128-135.

[9] Tutak W., Jamrozik A., Kociszewski A., Sosnowski M., Numerical analysis of initial swirl profile influence on modelled piston engine work cycle parameters, Combustion Engines 2007SC2, 2007, 401-407.

[10] Szwaja S., Study of combustion pressure pulsation in internal combustion engine fueled with hydrogen, Monograph nr 182, Czestochowa 2010.

[11] Tutak W., Thermal cycle of engine modeling with initial swirl process into consideration, Combustion Engines 2008, 1(132), 56-61.

[12] Kociszewski A., Numerical analysis of spark plugs number influence on selected parameters of combustion in piston engine, Combustion Engines 2008, 1(132), 61-68.

[13] Szwaja S., Bhandary K.R., Naber J.D., Comparison of hydrogen and gasoline combustion knock in a spark ignition engine, Int. J. Hydrogen Energy 2007, 32, 18, 5076-5087.

[14] Szwaja S., Combustion Knock - Heat Release Rate Correlation of a Hydrogen Fueled IC Engine Work Cycles, Proceedings of the $9^{\text {th }}$ International Conference on Heat Engines and Environmental Protection, Balatonfured, Hungary, 2009. 